Pesq. Vet. Bras. 30(12):1058-1063, dezembro 2010

Tópico de Interesse Geral

\title{
Metodologia aplicada na avaliação de fetos suínos abortados e natimortos ${ }^{1}$
}

\author{
Caroline A. Pescador ${ }^{2 *}$, Paulo Mota Bandarra ${ }^{3}$, Nadia Aline Bobbi Antoniassi ${ }^{3}$, \\ Adriana da Silva Santos ${ }^{3}$, Eduardo Conceição de Oliveira ${ }^{3}$, David Emilio \\ Santos Neves de Barcellos ${ }^{4}$ e David Driemeier ${ }^{3}$
}

\begin{abstract}
Pescador C.A., Bandarra P.M., Antoniassi N.A.B., Santos A.S., Oliveira E.C., Barcellos D.E.S.N. \& Driemeier D. 2010. [Methodology used in the evaluation of stillborns and aborted fetuses from swine.] Metodologia aplicada na avaliação de fetos suínos abortados e natimortos. Pesquisa Veterinária Brasileira 30(12):1058-1063. Laboratório de Patologia Veterinária, Faculdade de Agronomia e Medicina Veterinária, Universidade Federal de Mato Grosso, Av. Fernando Corrêa da Costa s/n, Coxipó, Cuiabá, MT 78069900, Brazil. E-mail: capescador@ufmt.br

This paper reviews information on necropsies in stillborn and aborted fetuses from swine. Aspects dealt with include sampling collection, necropsy procedures, gross and histopathological findings, some of which are of little or no pathological significance but often observed in the routine diagnostic work and misinterpreted as real or important lesions.

INDEX TERMS: Diseases of swine, reproductive failure, swine fetuses, stillbirth, diagnosis, gross findings, necropsy procedures.
\end{abstract}

RESUMO.- Este artigo revisa dados relativos à realização de necropsia em fetos suínos abortados e natimortos. Aspectos descritos incluem coleta de material, procedimentos de necropsia, achados macroscópicos e histopatológicos alguns dos quais de pouco ou nenhum significado patológico são frequentemente observados numa rotina de diagnóstico e geralmente interpretados erroneamente como lesões reais ou de importância.

TERMOS DE INDEXAÇÃO: Doenças de suínos, falha reprodutiva, fetos suínos, natimortos, diagnóstico, achados macroscópicos, procedimentos de necropsia.

\section{INTRODUÇÃO}

A suinocultura é uma das atividades mais importantes da economia brasileira. A região sul concentra $45,5 \%$ do re-

\footnotetext{
${ }^{1}$ Recebido em 6 de maio de 2010.

Aceito para publicação em 25 de julho de 2010.

${ }^{2}$ Laboratório de Patologia Veterinária, Departamento de Clínicas Médicas Veterinárias, Universidade Federal de Mato Grosso (UFMT),. Avenida Fernando Correa da Costa s/n, Coxipó, Cuiabá, MT 78069900, Brasil. Autor para correspondência: capescador@ufmt.br.

${ }^{3}$ Laboratório de Patologia Veterinária, Departamento de Patologia Clínica Veterinária, Faculdade de Medicina Veterinária, Universidade Federal do Rio Grande do Sul (UFRGS), Av. Bento Gonçalves 9090, Porto Alegre, RS 91540-000, Brasil.

${ }^{4}$ Setor de Suínos, Faculdade de Medicina Veterinária, UFRGS, Porto Alegre, RS.
}

banho brasileiro de suínos, e Santa Catarina é o principal Estado produtor com 20,4\% dos animais (IBGE 2010).

Taxas elevadas de abortos em granjas suínas estão entre as principais causas de falhas reprodutivas na suinocultura brasileira. Os abortos diminuem a produtividade do rebanho, principalmente, por diminuir o número de leitões nascidos vivos e por aumentar significativamente os custos sanitários (medicamentos) e as taxas de reposição de matrizes. A infecção pelo vírus da doença de Aujeszky em uma granja, por exemplo, pode resultar em perda total do rebanho para o produtor e suspensão de exportações de carne do estado atingido, afetando sobremaneira a economia local.

Aborto suíno é definido como o nascimento/expulsão da leitegada antes do término normal (fisiológico) de gestação da fêmea suína. O período médio normal de gestação é de 114 dias. Qualquer leitegada nascida antes do $110^{\circ}$ dia de gestação é considerada um aborto quando nenhum dos fetos sobrevive além de 24 horas (Sobestiansky et al. 2007).

Determinar as causas de aborto e natimortalidade em suínos muitas vezes é uma tarefa considerada difícil para muitos laboratórios que trabalham com diagnóstico. Parte desta dificuldade é atribuída ao fato de que somente 30$40 \%$ dos casos de aborto em suínos estão relacionados a agentes infecciosos e os outros $60-70 \%$ a fatores não infecciosos (Barlow 1998) como, por exemplo, causas tóxi- 
cas, genéticas, nutricionais e ambientais que frequentemente, não são detectáveis nas amostras enviadas para análise patológica.

A maioria dos fetos/natimortos não apresenta lesões macroscópicas e microscópicas significativas durante a necropsia. Dessa maneira, a interpretação de achados de forma inadequada pode interferir de forma negativa o diagnóstico final independente da suspeita clínica inicial. Sendo assim, o objetivo do presente trabalho é descrever a metodologia utilizada na análise de fetos suínos e natimortos, assim como caracterizar as lesões macroscópicas inespecíficas e os achados não patológicos ou de pouco significado que podem interferir negativamente no diagnóstico.

\section{ENVIO DE AMOSTRAS E EQUIPAMENTO}

A qualidade do serviço de diagnóstico está correlacionada diretamente com a qualidade de amostras submetidas ao laboratório. Na grande maioria dos casos de aborto e natimortalidade em suínos, é recomendado o envio de fetos inteiros e placenta refrigerados (não congelados) para o laboratório de diagnóstico. $O$ envio de fetos congelados interfere de forma negativa na análise histopatológica, pois os cristais de gelo formados geram artefatos teciduais, ocasionando problemas de visualização das lesões. Geralmente a investigação é limitada ao envio de pelo menos três fetos suínos abortados e todos os mumificados de uma leitegada afetada. Entretanto, a submissão de leitegadas inteiras, quando possível, é preferível, visto que quanto maior o número de fetos enviados, maior será a chance de chegar ao diagnóstico. Adicionalmente é importante lembrar que a infecção de somente um feto suíno da leitegada no útero da fêmea pode induzir o aborto e, sendo assim, a submissão de somente um único feto pode não resultar em diagnóstico.

Devido ao fato da maioria dos diagnósticos realizados a partir de necropsia de fetos suínos abortados serem de etiologia infecciosa, a coleta adequada de material é um parâmetro importante. Quando a necropsia é realizada no laboratório de diagnóstico, o patologista tem a possibilidade de coletar amostras apropriadas para a análise histopatológica, virológica, bacteriológica e molecular. Em situações no qual não é possível o envio dos produtos fetais, o procedimento de necropsia pode ser realizado na granja, entretanto, a coleta de amostras apropriadas se torna mais crítica.

Juntamente com os fetos suínos abortados e ou natimortos é importante o envio de uma ficha contendo dados referentes ao problema observado na granja como, por exemplo: número e idade das fêmeas afetadas, período gestacional, número da ordem de parto, status de vacinação da fêmea e rebanho, tipo de alimentação e se houve ou não algum problema prévio de doença reprodutiva no lote e ou rebanho. O fornecimento da história clínica completa pode oferecer ao patologista informações valiosas para se chegar ao diagnóstico.

O material necessário para a realização da necropsia é mínimo e consiste em ficha de necropsia, balança, régua milimetrada (para anotar as alterações observadas, verifi- car peso e medida dos fetos e ou natimortos), alicate, faca, tesoura, pinça dente de rato (para abertura das cavidades e coleta de amostras), seringa de $3 \mathrm{ml}$, agulhas hipodérmicas, sacos plásticos transparentes, tubo de vidro de 3 ou $7 \mathrm{ml}$, ependorfs, pote de plástico de preferência com a boca larga, solução de formalina a $10 \%$ e etiquetas (para a coleta de sangue, líquidos cavitários, tecidos e registro da amostra). É importante lembrar que para cada leitegada necropsiada o material a ser utilizado deve estar limpo e de preferência autoclavado para evitar possíveis contaminações cruzadas.

\section{PROCEDIMENTOS DE NECROPSIA E COLETA DE AMOSTRAS DE FETOS SUÍNOS ABORTADOS E NATIMORTOS}

É importante verificar o período gestacional da fêmea afetada. Geralmente infecções em útero causam morte fetal em diferentes idades gestacionais, enquanto, causas tóxicas e nutricionais geralmente resultam em morte fetal em fêmeas suínas de mesma idade gestacional (Barlow 1998).

Os procedimentos de necropsia são variáveis entre laboratórios de diagnóstico. Entretanto, é importante que os patologistas desenvolvam um protocolo de coleta consis-

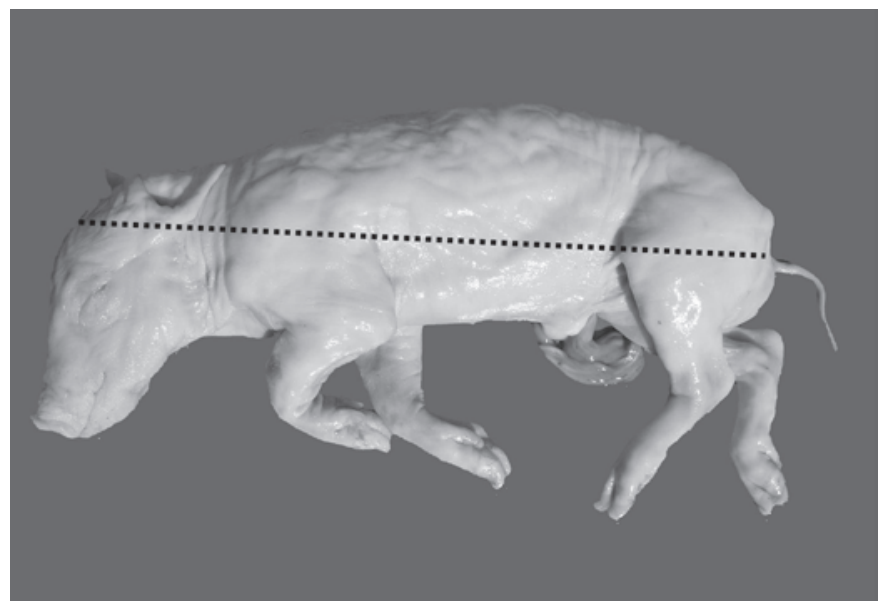

Fig.1. Feto suíno abortado. Medida da extremidade posterior do olho até a inserção da cauda.

Quadro 1. Estimativa da idade gestacional dos fetos suínos com base na medida da nuca até a cauda ou pelo peso do feto

\begin{tabular}{ccc}
\hline $\begin{array}{c}\text { Idade } \\
\begin{array}{c}\text { gestacional } \\
\text { (dias) }\end{array}\end{array}$ & $\begin{array}{c}\text { Medida da extremidade } \\
\text { posterior do olho até } \\
\text { inserção da cauda }(\mathrm{cm})\end{array}$ & $\begin{array}{c}\text { Peso }(\mathrm{g}) \text { sem } \\
\text { a placenta }\end{array}$ \\
\hline 34 & 4 & - \\
40 & 6 & - \\
52 & 10 & - \\
61 & 13 & 100 \\
70 & 16 & 190 \\
82 & 20 & 370 \\
91 & 23 & 557 \\
100 & 26 & 800 \\
\hline
\end{tabular}

${ }^{*}$ Idade gestacional aproximada $=21+(3 x$ a medida da nuca até a inserção da cauda [cm]). 
Quadro 2. Amostras necessárias em diferentes exames para o diagnóstico de aborto e natimortalidade suína

\begin{tabular}{lc}
\hline \multicolumn{1}{c}{ Amostra } & Exames realizados \\
\hline Tecido refrigerado & Exame \\
Pulmão, conteúdo do estômago & microbiológico \\
(2-3ml) e fígado & PCR para parvovírus \\
Pulmão e coração ou "pool" de & suíno e circovírus \\
pulmão, baço, linfonodo, coração. & \\
suíno tipo 2 (PCV2) & IFD ou PCR \\
Rim, figado ou pulmão & \\
para Leptospira spp. & Sorologia para \\
Líquido torácico (3ml) e & Leptospira spp. e \\
soro da mãe & Histopatológico \\
parvovírus suíno. & \\
Tecido fixado em formol & \\
Cérebro, tonsila, timo, pulmão, & \\
coração, fígado, baço, estômago, & \\
cólon espiral, rim, músculo & \\
esquelético, pálpebra, cordão & \\
umbilical e placenta & Imuno-histoquímica \\
Pulmão & \\
para parvovírus & Imuno-histoquímica \\
suíno, PRRSV. & \\
Coração & Imuno-histoquímica \\
para PCV2 & \\
Placenta & \\
para Clamydia spp. & \\
\hline PCR = reação de cadeia pela polimerase. IFD = imunofluorescência \\
direta. PRRSV = vírus da síndrome respiratória e reprodutiva \\
suína. "Pool" = mistura/conjunto de órgãos. \\
\end{tabular}

tente, que seja prático, dinâmico e facilite a detecção de lesões macroscópicas significativas e coleta de amostras.

A necropsia deve ser iniciada com o exame externo do feto ou natimorto. Antes da abertura das cavidades e coleta sistemática de órgãos, os fetos devem ser pesados e medidos da extremidade posterior do olho até a inserção da cauda (Fig.1) para estimativa da idade gestacional (Quadro 1). Este dado pode ser confrontado com a idade gestacional previamente relatada no histórico clínico encaminhado (Barlow 1998). Verifique externamente se os fetos enviados estão, em bom estado de conservação (fetos frescos), autolisados, macerados e ou mumificados e se há defeitos congênitos externos como, por exemplo, artrogripose e fenda palatina. Em seguida, coloque o animal em decúbito dorsal e faça uma incisão longitudinal na linha média desde o mento até o ânus. Rebata, lateralmente, a pele e membros. Em seguida, desarticule ambas as articulações coxo-femurais. Quando essas operações forem realizadas, os membros ficam estendidos lateralmente e o feto ou natimorto numa posição estável, em decúbito dorsal. Após é realizado a abertura das cavidades abdominal e torácica e observação das vísceras in situ, seguido da visualização de possíveis alterações macroscópicas. Neste momento inicia-se a coleta sistemática de material para os laboratórios de histopatologia, bacteriologia, virologia e biologia molecular (Quadro 2).

\section{LESÕES MACROSCÓPICAS DO ABORTO/NATIMORTO}

É de suma importância que o patologista saiba diferenciar lesões de pouco ou nenhum significado patológico de alterações que realmente podem contribuir no diagnóstico. Lesões macroscópicas frequentemente não são observadas em fetos suínos abortados e natimortos e quando presentes, não são patognomônicas de uma etiologia específica. Congestão e hemorragia na pele (Fig.2A) e tecidos devido à atonia das paredes dos capilares e injúria do endotélio vascular durante o processo de hipóxia fetal, hiperplasia do epitélio da língua (Fig.2B), combinado com a presença de líquidos na cavidade pleural, pericárdio e cavidade peritoneal são achados comumente observados, mas que dificilmente colaboram no diagnóstico (Holler 1994).

Um achado macroscópico frequentemente encontrado é a mumificação fetal (Fig.3A). Esta ocorre quando o feto morre no interior do útero após a formação óssea (30-40 dias de gestação) e não é expelido. Devido ao ambiente uterino estéril, o feto não apresenta alterações de putrefação, as vísceras podem possuir aspecto cinza (Fig.3B) e consistência seca a pastosa (Long 1986).

Lesões na placenta geralmente quando presentes são de origem inflamatória e usualmente conferem um aspecto opaco e a coloração tende a ser mais escura (marrom)

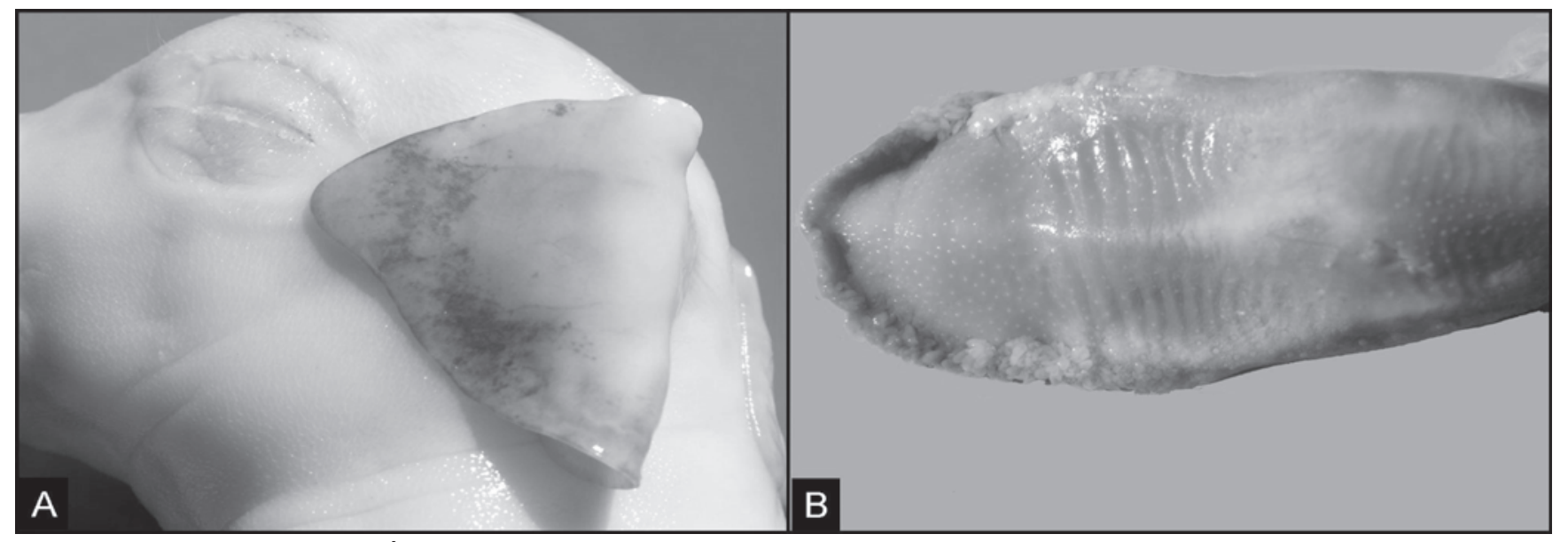

Fig.2. Feto suíno abortado. (A) Área de hemorragia na pele. (B) Proliferação do epitélio da lingua. 


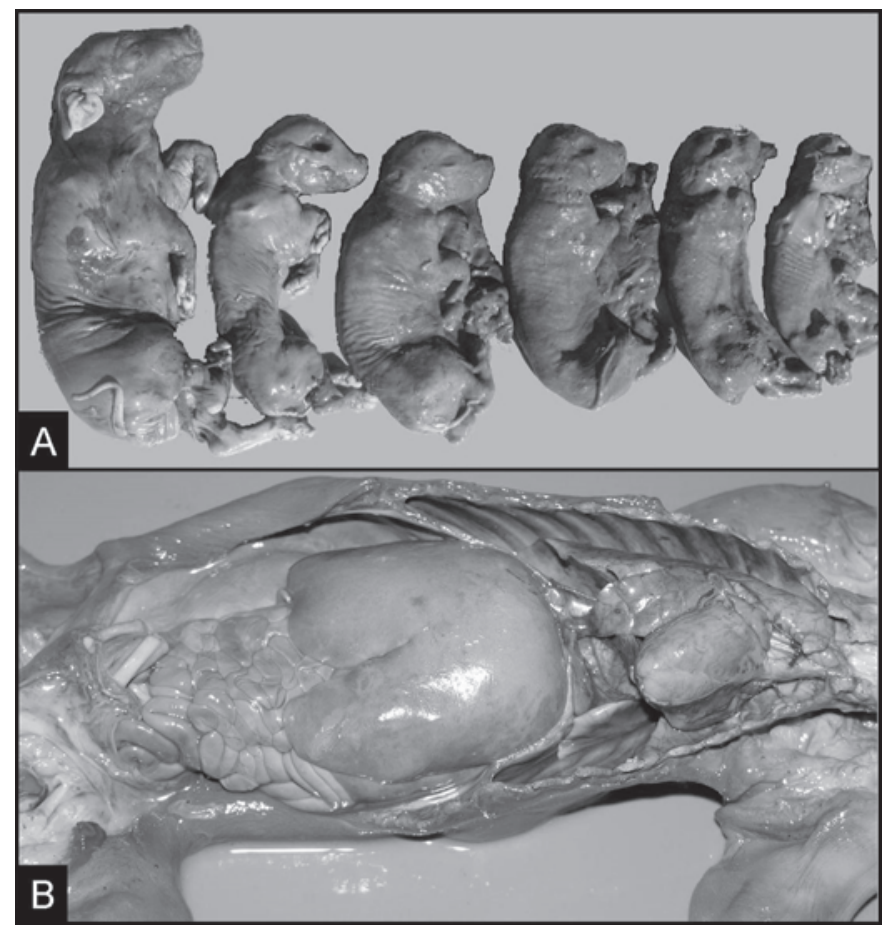

Fig.3. (A) Fetos suínos em estágio de mumificação fetal. (B) Abertura da cavidade abdominal e torácica de feto mumificado. Vísceras apresentando coloração acinzentada. que avermelhada. Hemorragias sob a forma de petéquias e equimoses também se fazem presentes neste tipo de alteração, entretanto, pode ser de difícil reconhecimento a nível macroscópico, devido ao grau considerável de autólise que este órgão pode apresentar.

Fisiologicamente, a parte coriônica da placenta suína apresenta coloração avermelhada, semitransparente e aveludada. Porém, variações normais na morfologia da placenta em suínos podem ser confundidas com lesões. Um exemplo disto são as placas mineralizadas (Fig.4A), de consistência macia e de coloração esbranquiçada frequentemente observadas próximas as junções das membranas alanto-coriônicas. Estas placas são depósitos normais de um material mineralizado (cálcio/ferro) finamente granular que podem ser confundidas com infecções micóticas (fungos do gênero Aspergillus). Adicionalmente, microvesículas (1-4mm de diâmetro), chamadas de aréolas (Fig.4B), ricas em glicoproteínas, das quais uma delas está envolvida no transporte de ferro da mãe para o feto, a uteroferrina são frequentemente observadas na superfície corioalantoide (Miglino et al. 2001) não havendo significado patológico algum.

Nos pulmões, indícios de lesões de pneumonia, são difíceis de serem reconhecidas macroscopicamente, devido à atelectasia pulmonar evidenciada nos pulmões fetais, entretanto, microscopicamente é facilmente observada. No

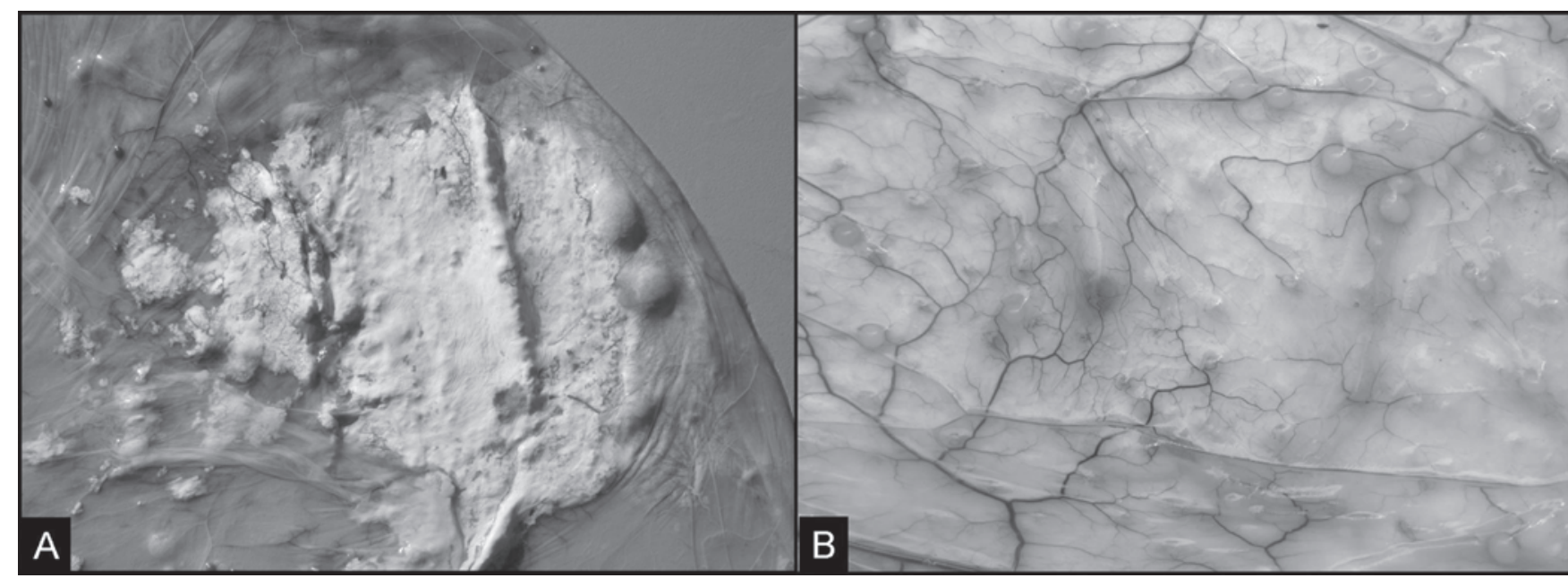

Fig.4. Placenta de fetos suínos abortados. (A) presença de placas mineralizadas de coloração esbranquiçada. (B) Superfície corioalantoide da placenta suína demonstrando a presença de microvesículas (aréolas).

caso de fetos natimortos a análise dos pulmões é de grande importância, pois possibilita a classificação do feto em tipo I ou natimorto pré-parto, feto tipo II ou natimorto intraparto e feto tipo III ou natimorto pós-parto, indicando assim se a morte fetal pode estar ou não relacionada a agentes infecciosos (natimorto pré-parto) ou a agentes não infecciosos e hipóxia fetal (natimorto intra-parto) (English et al. 1982). Na morte pré-parto os fetos são expulsos envolvidos em membranas fetais, as quais sofrem descoloração. Macroscopicamente, observam-se órgãos parenquimatosos friáveis e descoloridos; excessivo volume de líquidos serosangui- nolentos nas cavidades corporais e pulmões não flutuantes quando colocados em água. O natimorto intra-parto apresenta aparência normal ao ser expulso (Dial et al. 1992). E os pulmões apresentam coloração vermelho púrpura firmes e sem evidências de aeração e não flutuam na água (Carr et al. 1990). Nas extremidades dos membros, os leitões apresentam extensões de tecido queratinizado (apêndice decidual) (Fig.5A) nos cascos que no leitão vivo são perdidos dentro de 15 minutos após nascimento (Carr et al. 1990). Leitões que morrem pós-parto apresentam pulmões com evidências de aeração flutuando na água. No Quadro 3 es- 


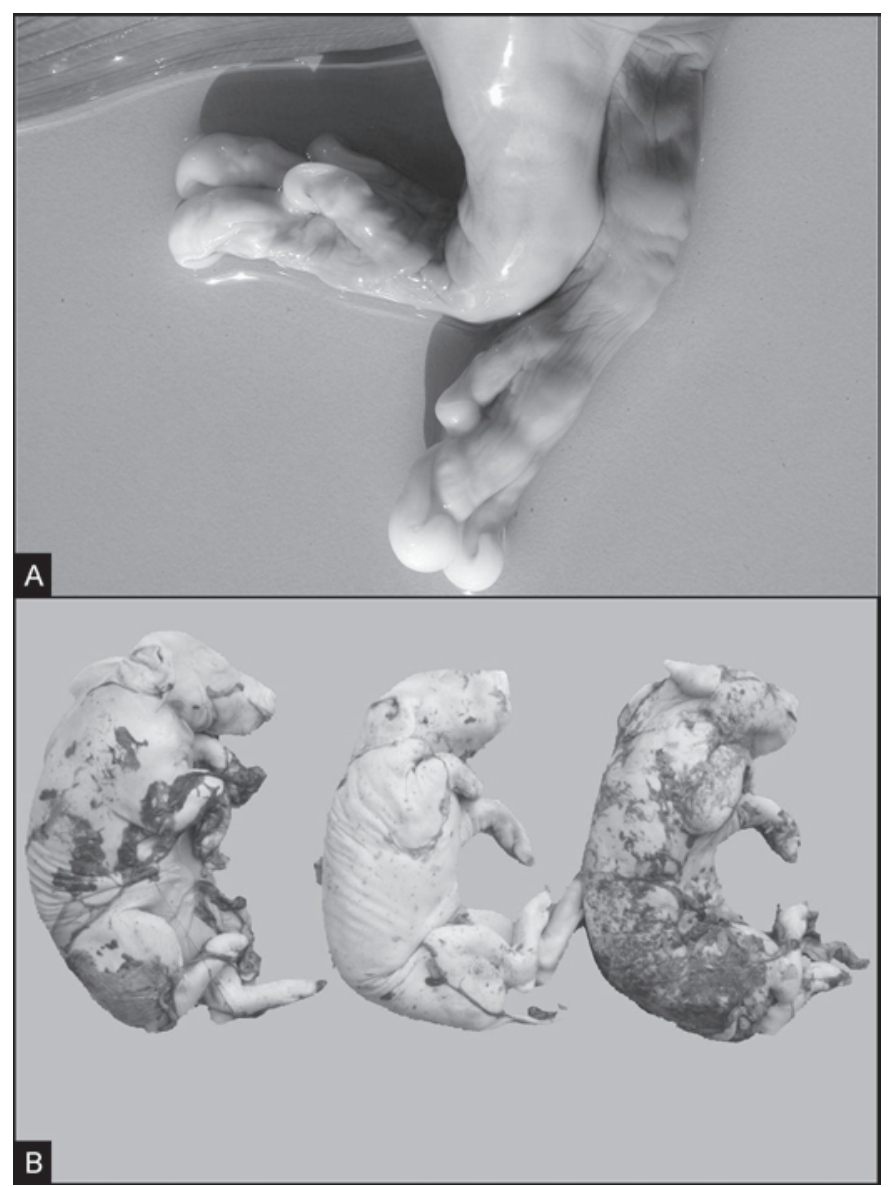

Fig.5. Feto suíno abortado. (A) Membros anteriores demonstrando a presença de apêndice decidual. (B) Pele, suíno natimorto tingido com mecônio.

\section{Quadro 3. Características externas do leitão ao nascer e principais achados macroscópicos à necropsia, relacionadas ao momento da morte (pré-parto, intra-parto e pós-parto)}

\begin{tabular}{|c|c|c|c|}
\hline & $\begin{array}{c}\text { Morte } \\
\text { pré-parto }\end{array}$ & $\begin{array}{c}\text { Morte } \\
\text { intra-parto }\end{array}$ & $\begin{array}{c}\text { Morte } \\
\text { pós-parto }\end{array}$ \\
\hline Pele & $\begin{array}{l}\text { Edema subcutâneo, } \\
\text { descolorida, presença } \\
\text { ou não de mecônio }\end{array}$ & $\begin{array}{l}\text { Pálida, seca, } \\
\text { cianótica,com } \\
\text { mecônio }\end{array}$ & $\begin{array}{l}\text { Manchada, } \\
\text { avermelhada } \\
\text { (hematoma) }\end{array}$ \\
\hline Olhos & $\begin{array}{c}\text { Profundos e } \\
\text { córneas azuladas }\end{array}$ & $\begin{array}{l}\text { Edematosos, } \\
\text { protuberantes }\end{array}$ & Normal \\
\hline Mecônio & $\begin{array}{l}\text { Tingindo } \\
\text { a pele }\end{array}$ & $\begin{array}{l}\text { Boca, narina, } \\
\text { traqueia e } \\
\text { estômago }\end{array}$ & - \\
\hline Pulmão & Atelectásico & Atelectásico & Aerado \\
\hline Membros & $\begin{array}{l}\text { Apêndice } \\
\text { decidual }\end{array}$ & $\begin{array}{l}\text { Apêndice } \\
\text { decidual }\end{array}$ & $\begin{array}{c}\text { Ausência de } \\
\text { apêndice } \\
\text { decidual }\end{array}$ \\
\hline $\begin{array}{l}\text { Cordão } \\
\text { umbilical }\end{array}$ & $\begin{array}{l}\text { Longo, com variável } \\
\text { grau de autólise }\end{array}$ & $\begin{array}{l}\text { Longo, } \\
\text { úmido }\end{array}$ & $\begin{array}{l}\text { Curto e } \\
\text { seco }\end{array}$ \\
\hline Órgãos & Variável autólise & $\begin{array}{l}\text { Edema } \\
\text { tecidual }\end{array}$ & $\begin{array}{l}\text { Variável } \\
\text { autólise }\end{array}$ \\
\hline
\end{tabular}

Fonte: Christensen N.H. (1994). Dead piglets: Aging dead piglets as an aid in problemsolving. Pig Hith Prod. 161:21-22.

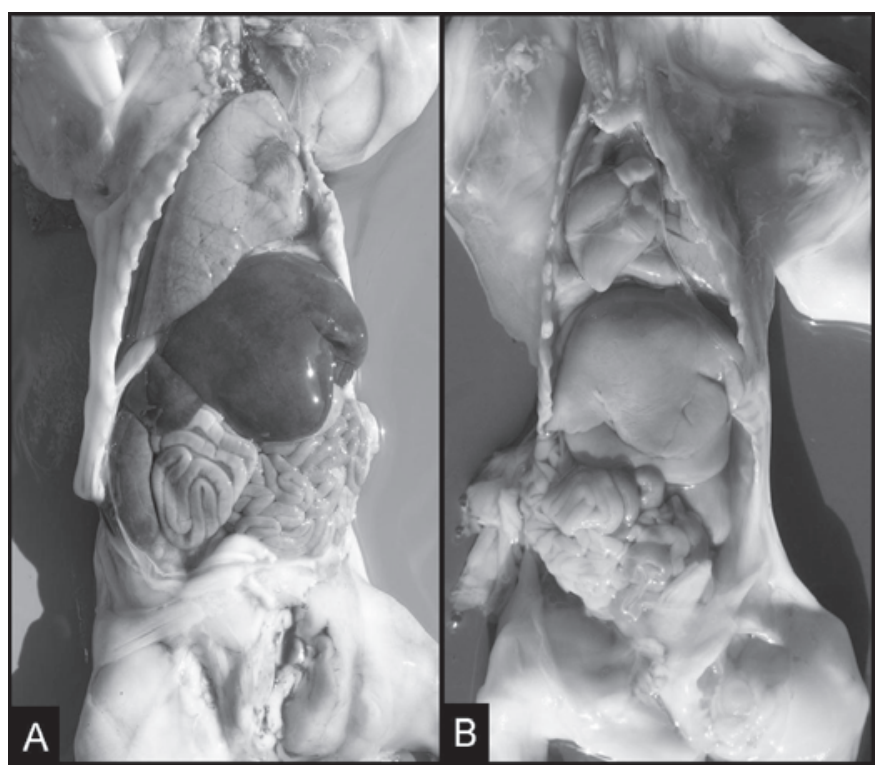

Fig.6. Feto suíno abortado. (A) Fígado normal. (B) Fígado amarelado e friável em processo de autólise.

tão sumarizadas as principais características macroscópicas de leitões na fase pré-parto, intra-parto e pós-parto.

Mecônio, também denominado de primeiras fezes do leitão, é composto por líquido amniótico, muco, pêlos finos que cobrem o animal, bile e células que se soltaram da pele e do trato intestinal, também pode ser observado macroscopicamente depositado sobre a pele (Fig.5B), narinas, laringe, traqueia e brônquios de fetos natimortos, na forma de um líquido de coloração amarelada. A presença deste líquido está associada ao estresse sofrido no interior do útero, levando a um aumento no peristaltismo intestinal e relaxamento do esfíncter anal ocasionando a contaminação e aspiração do líquido amniótico juntamente com mecônio em um processo patológico denomidado de hipóxia fetal (Alonso-Spilsburg et al. 2005). Ainda não está totalmente elucidada a causa da hipóxia, mas sabe-se que agentes infecciosos (bacterianos e virais) e rompimento do cordão umbilical através da utilização de fármacos útero-tônicos podem desencadear este quadro (Alonso-Spilsburg et al. 2005, Mota-Rojas et al. 2005).

Alterações de cor no miocárdio, conferindo ao músculo cardíaco uma tonalidade pálida a esbranquiçada, também deve ser interpretada com cuidado. Pois na grande maioria dos casos está associada ao livor mortis observado em alterações post mortem, não conferindo significado patológico algum, atrapalhando muitas vezes o diagnóstico. Entretanto, uma infecção pelo circovírus suíno tipo 2 (PCV2) pode ocasionar macroscopicamente áreas esbranquiçadas e dilatação ventricular cardíaca, que microscopicamente é caracterizada por miocardite não supurativa (West et al. 1999, Brunborg et al. 2007, Pescador et al. 2007).

Outras alterações como fígado pálido (Fig.6) e friável muitas vezes indicando apenas autólise em fetos mumificados e rins avermelhados com petéquias na superfície capsular verificado principalmente em leitões natimortos, 
que sofreram de asfixia fetal como resultado da redução do fluxo sanguíneo renal e consequentemente aumento do tônus aferente e eferente das arteríolas glomerulares (Alward et al. 1978) também são consideradas alterações frequentemente observadas.

\section{ACHADOS HISTOPATOLÓGICOS}

A análise histopatológica em tecidos de produtos fetais/ natimortos em alguns casos por apresentar graus avançados de autólise pode não fornecer subsídios suficientes para estabelecer um diagnóstico (Holler 1994). Entretanto, em alguns casos, a visualização de lesões inflamatórias como, por exemplo, pneumonia e miocardite ajuda a correlacionar a lesão ao agente infeccioso.

Outro fator importante que deve ser averiguado quando tratamos de diagnóstico em fetos suínos abortados é que a visualização de lesões histológicas juntamente com a utilização de exames laboratoriais adicionais como reação pela cadeia de polimerase (PCR), exames sorológicos do feto e da fêmea suína que abortou podem ser de grande valia para o estabelecimento do diagnóstico final.

\section{CONSIDERAÇÕES FINAIS}

Quando iniciamos a investigação de causas de aborto e natimortalidade em fetos suínos é importante reconhecer que existe um número variado de fatores que podem estar envolvidos, tanto sozinho como em associação. Por isso, a coleta e envio de forma adequada das amostras no laboratório muitas vezes é o ponto crucial para se obter um diagnóstico bem sucedido.

Laboratórios de patologia que trabalham com diagnóstico de fetos abortados sabem que muitas vezes este tipo de serviço é considerado um trabalho árduo e sistemático. Quando trabalhamos especificamente com a espécie suína, este serviço torna-se ainda mais laborioso, pois em termos de lesões macroscópicas observadas durante os procedimentos de necropsia, esta espécie quando comparada com as espécies ovina, bovina e equina é a que menos apresenta lesões significativas que podem contribuir no diagnóstico frustrando os patologistas ou aspirantes nesta ciência em geral.

Diante disso, saber distinguir lesões de pouco ou nenhum significado patológico de alterações que realmente possam indicar um processo infeccioso. Juntamente, contando com o auxílio de exames complementares como PCR, sorologia, microbiologia e um detalhado histórico clínico são de grande importância para desvendar as causas de abortamento verificado nas granjas produtoras de suínos.
Agradecimentos.- Aos demais membros do Setor de Patologia Veterinária da UFRGS pelo auxílio técnico. À Coordenação de Aperfeiçoamento de Pessoal de Nível Superior (CAPES) e ao Conselho Nacional de Desenvolvimento Científico e Tecnológico (CNPq, Proc.475130/ 07-3) pelo auxílio financeiro a este trabalho.

\section{REFERÊNCIAS}

Alonso-Spilsburg M., Mota-Rojas D., Villanueva-Garcia D., MartínezBurnes J., Orozco H., Ramírez-Necoechea R., Mayagoitia A.L. \& Trujillo M.E. 2005. Perinatal asphyxia pathophysiology in pig and human: A review. Anim. Reprod. Sci. 90:1-30.

Alward C.T., Hook J.B., Helmrath T.A. \& Bailie M.D. 1978. Effects of asphyxia on renal function in the newborn piglet. Pediatr. Res. 12:225-228.

Barlow A. 1998. A guide to the investigation of porcine abortion/stillbirth. In Practice 20:559-564.

Brunborg I.M., Jonassen C.M., Moldal T., Bratberg B., Lium B., Koenen F. \& Schönheit J. 2007. Association of myocarditis with high viral load of porcine circovirus type 2 in several tissues in cases of fetal death and high mortality in piglets: A case study. J. Vet. Diagn. Invest. 19:368-375.

Carr J. \& Walton J.R. 1990. Examination of stillborn piglets. In Practice 12:154-155.

Christensen N.H. 1994. Dead piglets: Aging dead piglets as an aid in problem solving. Pig Hith Prod. 161:21-22.

Dial G.D. 1992. Reproductive failure: Differential diagnosis. In: Leman A.D., Straw B.E. \& Mengeling W.L. (Eds), Diseases of Swine. $7^{\text {th }}$ ed. lowa, lowa State University Press, Ames.

English P.R. \& Wilkinson V. 1982. Management of the sow and litter in late pregnancy and lactation in relation to piglet survival and growth, p.479-506. In: Cole D.J.A. \& Foxcroft G.R. (Eds), Control of Pig Reproduction. Butterworths, London.

Holler D. 1994. Diagnosis of swine abortion. Swine Hlth Prod. 6:29-3.

IBGE 2010. Instituto Brasileiro de Geografia e Estatística. Disponível <http://www.ibge.gov.br/home/estatistica/indicadores/ agropecuaria/producaoagropecuaria/default.shtm $>$ Acesso em 20.1.2010.

Long G.G. 1986. Examination of the porcine fetus. Vet. Clin. North Am., Food Anim. Pract. 2:147-158.

Miglino M.A., Pereira F.T.V., Santos T.C. \& Carvalho A.F. 2001. A morfologia placentária dos suínos domésticos: revisão. Arq. Ciênc. Vet. Zool. 4(1):71-76.

Mota-Rojas D., Martínez-Burnes J., Trujillo M.E., López A., Rosales A.M., Ramírez R., Orozco H., Merino A. \& Alonso-Spilsbury M. 2005. Uterine and fetal asphyxia monitoring in parturient sows treated with oxytocin. Anim. Reprod. Sci. 86:131-141.

Pescador C.A., Bandarra P.M., Castro L.A., Antoniassi N.A.B., Ravazzolo A.P., Sonne L., Cruz C.E.F. \& Driemeier D. 2007. Co-infection by porcine circovirus type 2 and porcine parvovirus in aborted fetuses and stillborn piglets in southern Brazil. Pesq. Vet. Bras. 27(10):425429.

Sobestiansky J. \& Barcellos D. 2007. Doenças de Suínos. Cânone Editorial, Goiânia. 770p.

West K.H. 1999. Myocarditis and abortion associated with intrauterine infection of sows with porcine circovirus 2. J. Vet. Diagn. Invest. 11(6):530-532. 